A symmetrical system of rings, with some attention to simple elegance, would remove the offensive effect produced by the bent bars of mere blacksmith's work which now surround a single column.

But it is not specially to the state of the Chepstow Bridge that I wish to call the attention of the public. It is to the total want of practical knowledge as to the enduring power of metals, with which this bridge was built, and with which other such bridges must at present be built. We are totally without experiment on the danger of springing or buckling, and on the danger of bursting (now, I believe, for the first time brought forward). And we might perhaps consider such experiments as well falling within the province of those organised bodies whose union is based on the promotion of the most important determinations in civil engineering.

The Institution of Civil Engineers (with which body I have a much-valued honorary connection) has lately departed in some measure from the strict subject of engineering to which its attention bad been successfully given for so many years. I venture to suggest that this body might well take up the concuct of experiments bearing on engineering. The examination of the effects of force in mere crushing of external surfaces has been admirably prosecuted by American engineers. But the examination of bending and bursting, as the effects of end-pressure, is still open to the engineers of Britain. The funds of the Institution appear to be amply sufficient for such purposes, and the undertaking of them would undoubtedly be considered as honourable to the body.

The White House, Greenwich, November 17

\section{Physiology in Oxford}

A PARAGRAPH appeared in the Spectator of Saturday, the Ioth inst., on the Oxford memorial concerning the University Physiological Laboratory. That part of it which affects Magdalen College appears to me to rest upon erroneous information, and is certainly calculated to spread an entirely false and misleading impression of the attitude of this College in the matter, and of the University in general.

If you will allow me to quote the paragraph, and at the same time give you the actual facts, I think you will easily form an opinion on the real state of the case.

The paragraph states that the signatures were received "from members in Oxford and its suburbs, and the rest from a circle of about fifteen miles round."

The fact is that the signatures are not drawn exclusively from either the smaller or even the larger area, one of the so-called Ma:dalen signatures being that of a member of the Hereford Cathedral choir.

The paragraph goes on to say :- " "We are told that Magdalen men have igned it more numerously than any other College but one, and, in proportion to the size of the College, more numerously than any. Now, as Prof. Burdon Sanderson is ex officio a Fellow of Magdalen, and as Magdalen has for years past had a physiological laboratory of its own, this popularity of the memorial among Magdalen men is highly significant."

On this I have to remark that the signatures are representative neither of the governing body of the College, nor of its resident members.

The governing body of the College consists of the President and twenty-four Fellows; of these twenty-five three alone have sioned the memorial. The resident members, as shown by the list of congregation, number twenty-two; of these twenty-two only six have signed.

Finally, as regards the last paragraph, it is true that Mag. dalen Colleve has for years past had a physiological laboratory of its own, and it is further true that the University teaching of physiology has been carried on there, previous to the advent of Dr. Burdon Sanderson, for years past under a Grovernment licence with the full and express consent of the whole governing body of the College, a fact which is indeed significant, but hardly in the way in which the Spectator appears to have been informed.

Magdalen College, Oxford, November I $_{5}$

\section{Green Sunlight}

Mr. G. H. Hopkins' observation that the parting ray at sunset is sometimes brilliant emerald-green brings to $\mathrm{my}$ memory a somewhat similar experience. On September 13 1865, watching on the summit of the Rigi for sunrise, I caught the very first possible glimpse of the sun's disk as, on a very clear morning, he emerged from behind the sharply.defined outline of a distant mountain. The very first rays, although necessarily proceeding from the comparatively obscure limb of the sun, were dazzlingly brilliant, and of a superb emerald green colour. But almost instantly, as more of the sun appeared and his light grew sensibly more intense, the green passed away or was merged in the yellowish white of ordinary sunlight.

In my case I do not doubt the phenomenon was purely subjective, for before sunrise the sky was all lit up of a magnificent crimson hue. Every one must have noted how the moon when surrounded with bright crimson clouds looks more or less decidedly green.

A very striking effect of this sort, like the others an example of the well-known visual phenomenon of "accidental colours," may be artificially obtained, any time the moon shines, by burning an ordinary "blue" signal light. After my eye had been intensely excited by such a light close at hand, I have seen the moon, near or at its full, of a deep plum colour, by which $I$ mean the colour of the bloom on a black plum or on a well coloured Hamburg grape. Or, in place of these, the viol.t of my friend Prof. Piazzi Smyth's exquisite chart of colours in his "Madeira Spectroscopic," or the bleu violet of Chevreul's chromatic circle. I recommend the experiment as easy of performance and exceedingly beautiful in its effects. Possibly a small blue light would suffice. But, on the occasion to which I have referred, certainly not less than thirty ounces of nitre, ten of sulphur, and five of black antimony sulphide were employed. These, mixed in fine powder, may be burned in a case about six inches high and four in diameter; of course in the open air, and where no mischief may accrue from an intensely hot and volu. minous flame.

In a communication made to the Royal Society of Edinburgh in I852 (Trans. vol. xx. pp. 445-47I), I adducsd evidence to prove that a continuous thin layer surrounds the sun's photosphere, of which upturned portions form the red protuberances seen at total solar eclipses; and I then showed that if the well known darkening of the sun's limb be due to absorption in his atmosphere, it can only be caused by such a thin envelope. The existence of this envelope, the sun's chromosphere, is now fully established. If, from the red colour of its upper portions, we may infer the resultant tint emitted by the whole to be red, then, by a well known law, the discolouration of the sun's limb due to its absorption should be of a greenish hue. But such an effect would necessarily be but slight, and could not explain the brilliant green witnessed on the Rigi. Nor do I recollect any instance where the first emerging rays of the photosphere at the end of a total eclipse have been observed to be green.

Ardchapel, Dumbartonshire, November 8 WILLIAM SWAN

A LeTTER from Barinas, Venezuela, states that on September 2, from daylight until noon, and from $3 \mathrm{p} . \mathrm{m}$. to sundown, the sun appeared like a globe of burnished silver. Between noon and three o'clock it was of a bluish-green colour. This appear ance in the western hemisphere seems to dispose of the suggestion of the Java eruptions as the cause of green suns in India. HYDE CLARKe

\section{Mangrove as a Destructive Agent}

As I have never seen the mangrove mentioned but as a conservative or productive agent as regards geological change, it may be interesting to readers of NATURE to hear of its acting in a contrary direction.

In several parts of eastern tropical Africa, where the shores are mostly of upraised coral limestone, I have noticed the effect of mangrove in eating away this rock, but nowhere bave I seen it so well marked as in the Island of Aldabra, some two hundred miles to the north-west of Madagascar, and which I surveyed in I878.

Aldabra is an upraised atoll about twenty-two miles long, and presents low cliffs of about fifteen to twenty feet of solid coral rock to the sea and also to the lagoon, which is, at low water, nearly dry 